\title{
THE COMMUNICATION AND SOCIAL NETWORK FLOWS APPROACH FOR DISRUPTION PREPAREDNESS
}

\author{
MARYA L. DOERFEL \& JACK L. HARRIS \\ School of Communication and Information, Rutgers University, USA
}

\begin{abstract}
Resilience officers are an emerging profession who work on behalf of municipalities, cities, institutions, transportation hubs, businesses, etc. Their mission involves disaster preparedness, response, and management, in the hopes that their work minimizes the impacts of disruption. Their work is inherently communicative. Coordinating resilience involves local leaders, government agencies, response agencies and first responders, as well as the community's local groups, non-profits, and businesses. These organizations are connected in networks that are dynamic - partnerships are activated and go dormant, the nature of the relationships evolve (e.g., from cooperative to competitive, friendly to adversarial), the overall system varies in terms of overall activity (i.e., densely to barely connected), and leadership can vary from highly centralized around one or a few key organizations to decentralized with various clusters of partners. A common theoretical dilemma in social networks is that different network structures offer different advantages and disadvantages. The advantages and disadvantages are often in tension with each other and dependent on the situation. Yet building and maintaining relationships is crucial to the efficacy of resilience work. Moreover, these relationships exist within larger stakeholder networks comprised of organizations that are nested in their own set of networks, adding complexity to the challenges of such work. These theoretical dilemmas mean that practitioners need to be more nuanced in understanding organizations and ways to communicate to build social networks as part of preparing for the inevitable disruption. In this paper, we take a communication and social network theory perspective to propose a FLOWS approach to managing resilience. We draw on internal organizing forms (e.g., bureaucratic; networked), social capital, and stakeholder theory as concepts that pertain to communication and information technology use. Together, these theoretical frames point to the FLOWS approach to action-oriented resilience organizing.

Keywords: resilience, communication, social networks, social capital, bureaucracy, social media, communication and information technology, stakeholders.
\end{abstract}

\section{INTRODUCTION}

In careers and at work, building relationships matter. We have business cards to pass out, we connect with our contacts through online networking sites, and long before social media, professional's address-book - their "Rolodex" - size was a good indicator of her business acumen. Today, the more opportunities technology gives us to connect to people, the larger our social and professional networks can appear. At work, we now see large corporations and traditionally bureaucratic institutions adopting matrix structures or other networked forms of organizing, where employees are expected to answer to multiple bosses, attend networking events, engage on knowledge management systems or internal social media platforms, build unique teams as unique problems arise, and have the flexibility to move between different teams for different projects while staying on top of the complex details and expectations of each.

Organizations are also pressured to build up networks of partners and consortia for leveraging power in the broader economy, engaging in inter-organizational relationships for joint problem solving, community engagement, consulting and outsourcing, and most recently, for managing resilience. Like people, organizations use relationships with other organizations to leverage information and manage their survival in what are often ever-changing and volatile environments. Whether it is individuals working in various task 
groups, teams or organizations building up alliances with others, the task of building and maintaining relationships across social networks can be daunting. Managing with networks, whether considering individuals' professional networks or interorganizational networks, suggests that networks are different and are a departure from the hierarchies and formal structures of traditional organizations [1]-[3]. This understanding continues to be developed through empirical research on social networks and organizations with research showing that network organizing involves both planned, top-down network designs for collaboration, and more spontaneous, emergent designs that arise from more casual social and organizational interactions [4]-[6].

Simply put, hierarchies co-exist with networks, whether considering internal relationships among different members of an organization or of the relationship an organization has with its external stakeholders. Rules, regulations, and formal policies are used to create predictable environments and are designed to manage uncertainty, demonstrate fairness and equality at work, and impart some level of clarity about work and work processes. Social networks are the relational aspects of work, authority, and information exchange, and sit "on top of" or are used as "work arounds" of more formal organizational and communication structures. These relationships are the ways in which people make sense not only of their external environment, but of the organizational environment or context in which they are operating [7], [8].

This essay presents an organizational communication model for managing resilience. We integrate concepts from both social networks and bureaucratic organizing approaches to address real-world challenges resilience officers face when tasked with making their organization and community "resilient." We propose the Social Network FLOWs approach for managing the collaborative processes that are both informal (they use social networks) and formal (such resilience building happens in top-down, regulated, policy-bound, bureaucratically controlled structures) at work and with external stakeholders. The FLOWS approach identifies five considerations for managing resilience: Formal and informal

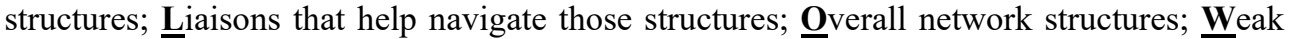

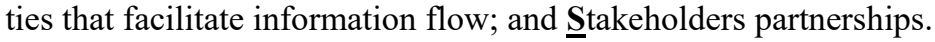

We address both individual level and interorganizational levels with respect to the ways work is designed and managed (e.g., formalized reporting structures) and accomplished (e.g., social networks). We point to those control mechanisms that are normally viewed as organizing features inside businesses, which are similarly at play at the interorganizational level. A great deal of interorganizational scholarship considers institutionalized exchange among organizations that does not necessarily involve individual activities (e.g., [9]), while other interorganizational research, like advice networks and collective action networks, take into consideration the actions of individuals as agents of their organizations [10]-[13]. We proceed by comparing hierarchies as a way to express the assumptions reflective of more formal approaches to control and organizing and with social networks as representative of the generally informal mechanisms that support getting collaborative work done. These common organizing features in both internal and external relations reveal the ways communication can be more strategically integrated in resilience planning and management. We present the social networks FLOWs model for practitioners to use to evaluate, plan, and improve their communication and social networks.

\section{FLOWS "F" AND "L": FORMALITY OF STRUCTURES AND LIAISONS}

The $\mathrm{F}$ in the FLOWS approach refers to the relative formality of structures aimed to support organizing and coordinating work. Formal organizing has qualities reflective of [14], bureaucratic forms, where centralized decision making, specialization, routine procedures, and written policy and documentation function to coordinate and control work [2], [15]. From 
a communication point of view, who talks, interacts, and coordinates with whom is then influenced by these specifically designed structures and through communication, such structures and the communication that generates context get reconstituted [16]-[19]. The emergence of communication networks, then, has been historically discussed in terms of the way work actually gets done [20], [21]. Networks are thus partly constituted through the formal structures of coordination and control.

While the underlying assumption is that the informal networks operate simultaneously with the formal structures that design coordination and control in organizations, external stakeholder relationships, particularly inter-organizational relationships, have come to be treated as emergent (cf. [22] for exceptions). Interorganizational networks emerge in order to manage environmental uncertainties, leverage capacity through sharing and controlling resources, and glean knowledge and best practices to ensure their own survival [1], [23]-[29]. But organizations also have relationships that are more formal - regulatory bodies, policy compliance, and legal arrangements are formal and are bureaucratic. In the biotech industry, for example, case study work has shown that there are dualities between collaboration and information sharing, which are social (network) and emergent processes, and negotiating product management regarding who "owns" the outputs, a decision that often is legally negotiated [30]-[32]. Within the public sector, organizations may enter into network partnerships in order to manage funding uncertainties, share expertise and knowledge, or even share work among other members of a social services network based on functional and operational expertise [33]. Specifically, top-down influences based on legal arrangements can both direct and undermine the ability for social networks to emerge organically. Such relationships can become "increasingly encumbered and influenced by organization-level practices and policies" [30].

Yet, a great deal of the real work happens in the informal, unofficial networks, despite mandates such as those that require publicly held companies to report their business alliances [34]. In the realm of interorganizational networks, a common observation is the emergence of a dominant core elite with less influential organizations on the periphery of these networks. There is a long history of understanding the status differences that emerge in organizational networks [1], [23], [29], [35], [36], and that in the emergence of status differences, power, control, and the "explicitly acknowledged and enforced status hierarchy" [37], come to be recognized and reified through communication.

\subsection{Reporting structures}

In hierarchies, managers and supervisors are expected to oversee work, be accountable for productivity, and reporting the successes and needs of their units to their bosses. Up the chain these reports go until they reach the top tier of the organization, where resource allocation, turnover, and growth are determined then disseminated back down through the layers of the company. On the other hand, organizations that adopt a network approach to organizing idealize a different set of arrangements. The team is where pressure to perform is monitored, decentralized decision making and job design means that workers are valued for their own intellectual contributions and ability to function independently. Related, power and authority emerge from liaisons (as discussed above) in the social networks - those who have information access to a variety of different groups across the organization, as opposed to the bosses who have the authority vested in their designated role. liaisons become more powerful through their ability to control what information flows to the parts of the network that would not otherwise be connected. Moreover, liaisons are often opinion leaders and therefore have social influence too. The structure of the social network emerges out of its members' 
information needs and assumptions about who knows what as well as who knows who knows what [38], [39]. While communication in hierarchies is valued when it is clear, unambiguous, and reduces uncertainty, communication in networks recognizes that meaning and understanding are ambiguous, negotiated, and equivocal. Liaisons are thus the translators of the information, because they understand multiple points of view as a result of the ties they have across the organization.

\subsection{Resilience organizing around and through bureaucracies}

Resilience plans include concerns with accountability, control, and clear lines of authority - by design, they are bureaucratic. Even the best laid plans do not anticipate all aspects of what response - and being resilient through it - will look like until the event is unfolding. Both plans and improvisation, often through networks, get activated. Networks emerge and may work in spite of or alongside authorities imparted with response leadership. For example, after 911, the New York City harbor became an active space where some mariners started shuttling people from Manhattan to New Jersey. These mariners leveraged their networks to facilitate getting people all the way home (not just to the shore), while others waited for confirmation from the coastguard as to whether they should help, and then proceeded on cue from authorities [40]. On board radios facilitated emergent groups' abilities to coordinate their actions. A resilience manager needs to both recognize standard operating procedures (bureaucratic plans) and the informal, social responses that emerge through networks of people. These emergent responses and active social networks may not even be known until the event is unfolding. Given the co-evolving nature of bureaucracies and social networks, a resilience action plan should:

- Know the relevant or accountable bureaucracy and the plan that was predesigned to facilitate efficiency, clarity, and accountability.

- Know what communication and information technologies are used in the community by its members.

- Be ready to deputize or engage emergent networks ready and equipped to help.

- Identify liaisons that move information and can translate that information from various parts of the system.

This section addressed general organizing assumptions of bureaucracies and networks. A good part of planning is knowing the network of salient stakeholders, their formal structures, and liaisons who can "translate" because they have direct access to different components of the network. There are ways to assess existing networks with a critical eye towards balancing opportunities that your network affords while also controlling the degree to which your networks may overwhelm you with information overload and relationship management. But first you must have a good sense of what your network is. How to identify and evaluate a social network and the relationships they comprise is discussed next.

\section{FLOWS: OVERALL NETWORKS AND WEAK TIES THAT CONNECT THEIR PARTS}

Lately, the term social capital is used so indiscriminately that its generic usage misses nuances in the quality and nature of the relationships that generate social capital. It's not enough to strive for having "a lot" of social capital - that becomes a futile challenge and doesn't answer the question of how much is enough? Rather than counting up relationships, a better way to think about building and maintaining social capital is to think about how much 
confidence you have in your relationships. Can you call upon people and organizations in your network when they're needed? Would you help those same partners if they called upon you? Essentially, how open is your network to unique information? We build social capital by building up relationships that allow us to tap into a system of networks perpetuated through personal and professional contacts. Social capital has several dimensions and is a way to assess an overall system of networks (structural social capital, structural holes), specific relationships that are the links between network members (relational, bridging, and bonding social capital), and the point of view of any one network member (cognitive social capital) [41]-[43].

\subsection{FLOWS "O": overall network thinking}

To think at an overall, system-level, means to think beyond your own network and instead, consider relationships your contacts have and the relationships your contacts have with others (see Fig. 1a and Fig. 1b). Knowing the overall structure of a bureaucracy is similar to examining the organizational chart. While bureaucracies map out the hierarchical relationships and identify key roles - managers, subordinates and the reporting structures of who should report to whom, the overall social network refers to the informal map of relationships that happen more organically [15]. The network in Fig. 1a shows a focal organization and its primary stakeholders. It's important to know who those organizations are, but it is also important to recognize that considering only the focal organization's relationships misses what Fig. 1b shows - that those primary stakeholders have other relationships and their relationship with the focal organization may not be primary to them. The social network can be completely connected, where everyone has direct ties to everyone else to not at all connected, where there are no relationships in the system. What lies in the middle of these two extremes are myriad ways in which the social structure reveals a map of relationships among its members. Over time, networks that tend to be more connected also tend towards closure and sustain themselves increasing deep trust, and mutual understanding and knowledge, which can enhance performance [44], although such relationships risk groupthink if norms of loyalty and commitment to relationships prevail over task orientation [45]. Some research has shown that closed networks fortified by information brokers can ward off groupthink - they benefit from these brokers that "fill" structural holes [46].

\subsubsection{Efficiencies that hold together overall networks}

Having structural holes in a network suggests a certain efficiency regarding the ability for information to flow through the network. Ron Burt advanced the idea of structural holes in an overall network as a way of recognizing the value of brokers. Brokers refer to those liaisons (see above section 2.1) in the network who facilitate its flow by filling structural holes - they have ties that connect otherwise disconnected groups. Think of the airport system as a network - there are a few centralized hubs and some 15,000 other airports and airfields throughout the US. Those few hubs hold the system together and support its efficiency. As brokers in the airport network, they need massive capacity to support their highly centralized role. But those brokers also have an advantage because increased traffic brings them additional resources through revenue from airlines in addition to passengers who pass through their airports, spending billions per year in US airports [47]. And when something happens to one of those hubs (bad weather; some other emergency), the entire system can feel the impacts. Under normal times, the overall network is efficient and effective in moving people. 

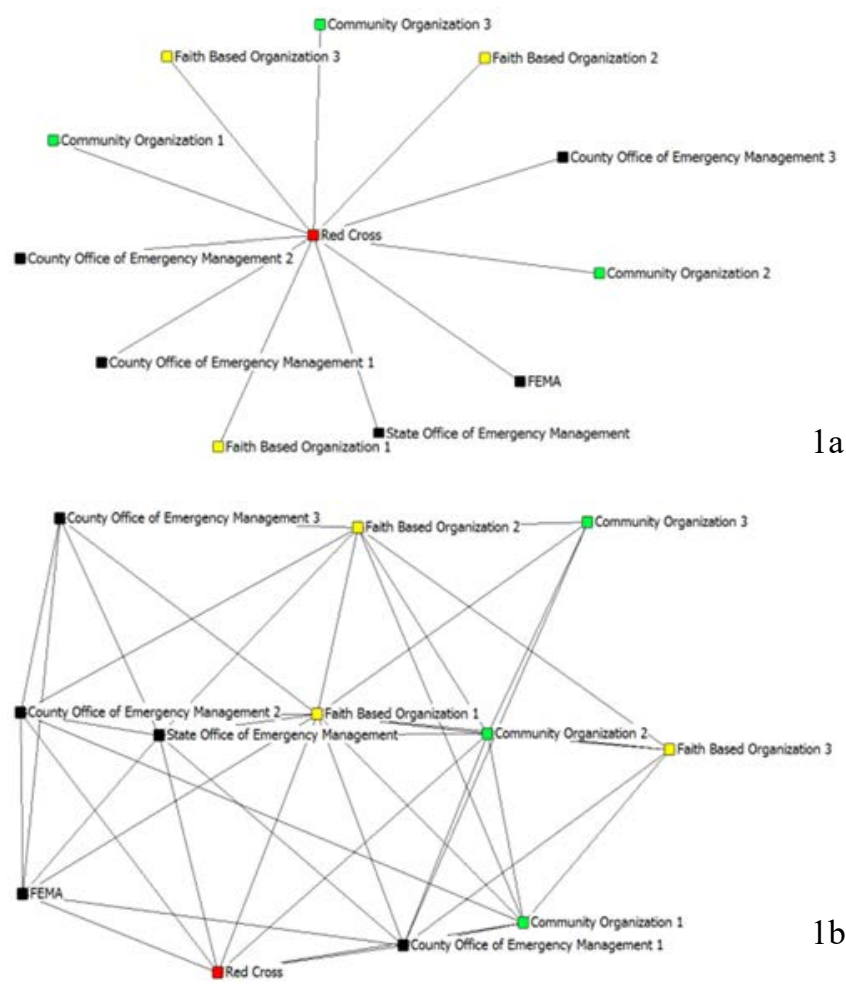

Figure 1: 1a. Hub and spoke network; 1b. Networks of networks.

The same concern with load and flows applies to social networks. Brokers are highly central relative to other system members and need capacity to support that role in the network, with advantages and disadvantages to having such a structure and key members being burdened and advantaged by their brokerage role.

An overall network that has a balance of structural holes brings a level of efficiency to information access. There is no need to know everyone in a partner organization or field of stakeholders, for example, if one key informant (broker) from that organization or group can relay pertinent information. The cost of networks relying on brokers is control - brokers may be gatekeepers who may actively or passively decide about what information is salient to move through the network. Too many structural holes can lead to firm failure while a mix of "arm's length" broker ties with stronger ties appears to reduce that risk [48]. Yet efficiency in the overall system's network relies on brokers who facilitate information flows so that it moves quickly from one part of a network to other parts. The cost of such efficiency is that information flows are constrained by the ability, willingness, even whims, of the brokers that fill structural holes.

It seems like a highly efficient overall network held together by a few key brokers has advantages. But over time, the more the overall network relies on a few key brokers for information, the more capacity (time, energy, money) brokers need to manage that position [49], which could then be an invisible cost to the overall system. Moreover, the more network members seek to connect to that broker, the less efficient the network becomes. The centralized network in Figure 1a illustrates this paradox. The more a network member 
becomes reputed as being a relied upon broker, the more other members may turn to that broker directly for their information. Over time, the overall structure of the network shifts from being decentralized to being centralized around one or a few key brokers. The system's structure shifts from being effective in its decentralized structure to being reliant on a select few brokers. Not only do those brokers need to keep up with more and more relationships (a risk to their reputation if they disappoint those relational partners), the system now relies on more limited points of view, the brokers' judgments on what information is worth transmitting, and on their interpretation as they disseminate that information.

Given the advantages and disadvantages of being a broker and relying on brokers, the resilience strategist should:

- Estimate primary stakeholders and their networks.

- Does the overall network have enough organizations filling structural holes so as to avoid problems of capacity and information access?

- If your organization is a broker, how much capacity do you have dedicated to maintaining flows through the overall network?

- Is the network tending towards closure? What ways could the network "open" to allow for more.

In sum, the overall social network of a system is often viewed as the way information actually flows, in contrast to the hierarchy of relationships that lay out how information should flow in and across organizations. System-wide social networks are a bird's eye view of all the relationships; not just from one ego-centric point of view. The social network structure could tend toward closure which has its own advantages and limitations. On the other hand, the system can become so centralized that a few key brokers end up with control and power as liaisons that move information and translate its meaning. Such a centralized system overly burdens that central actor but also with that burden comes power to control the flow of information.

\subsection{Flows $\mathrm{W}$ : weak ties, access, and relational quality}

Where the overall network can provide and limit opportunities (e.g., a closed network might limit opportunity to add relationships), dynamic relationships can shape the structure of the network. Social capital is inherently relational [43], and is both a network quality and a function of relationships that define network links. Relationships can include mutual liking and how close members feel to each other, the extent to which partners confide in each other, and the degree to which norms of reciprocity prevail in the relationship [50]-[52]. Such relationships also vary in their ability to build deep trust and mutual confidentiality. Weaker ties provide a bridging social capital function while strong relationships offer a bonding function in the network. Networks with just enough structural holes to facilitate information flows can be more creative or innovative, but only to a point [53]. Bonding ties are by definition stronger can be arrayed along different qualities including (a) affect, (b) confidentiality, (c) reciprocity, and (d) time, while bridging ties tend to be less distributed along these four relational dimensions.

Just knowing that relationships - social networks - are accessible can be vital to resilience planning and decision making. In post-Katrina New Orleans, for example, organizations felt confident about the timing of their return after their state-imposed city-wide exodus. "Just knowing" others in their network would be back gave New Orleans organizations the confidence to return and restart [11]. Knowing potential ties will be available gave profound 
confidence during an otherwise turbulent, highly uncertain time. Structural social capital is social capital in its simplest form: a tie or set of ties exists. Structural capital sets the tone for action with a confidence that potential relationships can be (re)built. Information and communication technologies (ICTs) facilitate assessing structural social capital. Social media, alone, however is not sufficient. When major events undermine connectivity, using a mix of word-of-mouth, texting, and social media increases the efficiency and effectiveness of organizational rebuilding [54]. Just knowing ties exist is only partially sufficient. Understanding that relationships hold qualities like trust, reciprocity, history, mutuality, are at the heart of bonding the network. We next turn to bonding social capital.

Bonding social capital refers to those trusted, strong tie relationships where norms of reciprocity and mutual confidential sharing prevail. In a working relationship, bonding ties build deep trust, loyalty, mutual knowing and normative in-group behavior. The idea of groupthink - that social pressures of a group have greater pressure for members to conform and be loyal lead to grand mistakes and low-quality decision making applies in the extreme cases of bonding social capital. But evidence also shows that tie strength can increase information sharing in teams that have high levels of interdependence with respect to their work [55]. Bonding social capital is similar to the above idea of closure because bonding ties reflect the relational activities that perpetuate network closure in a recursive cycle over time.

Bridging social capital refers to the weak tie relationships that provide access to information beyond one's own direct contacts in their social network. Weak ties have been shown to facilitate the flow of information through networks [56]. They have been shown to improve performance when teams have a mix of strong and weak ties and their tasks are interdependent [57]. Identifying weak ties can be related to the success of past relationships [58]. Identifying those connections can be done by considering the past and current project partners and the quality of work that resulted in those collaborations.

Given the overall system structure and the ability for weak ties to carry information across the network, resilience officers should consider:

- Does your network have an overall structure that facilitates the flow of information through it?

- What weak tie relationships provide information from other parts of the network? Do these ties require ongoing attention and relational maintenance?

- Do such ties also know each other, thus "closing" the network or do they broker information from groups and other networks of which your organization is not a part?

- What bonding activities support trusting, deep relationships where there is space to co-create and plan for mutual aid during disruptions?

\section{FLOWS “S:" STAKEHOLDER ENGAGEMENT}

When Freeman [59], articulated the value of external relationships for strategic management, it was natural for organizations to think of themselves as a hub surrounded by organizational stakeholders dependent in some way upon the focal organization. This ego-centric point of view overlooked what networks map out - that a focal organization's partners have their own relationships, too. A social network point of view about internal and external relationships helps reveal the map of relationships and stakeholders' relationships, too. Resilient planning is about thinking beyond the organization's egocentric world. Weak tie networks provide knowledge redundancies and support information flows. Strong ties can support rebuilding through mutual understanding of what your organization may need [60]. Networked thinking also helps resilience officers anticipate tensions - some stakeholders may have stronger ties 
to other organizations which may impact their priorities regarding their networked partnerships during disruptions.

Stakeholders, themselves, range in terms of their priorities and interests in your organization, which has implications for how to engage them in decision making and resilience processes. Stakeholders vary in terms of their interdependence with your organization, which implies the degree to which they might be engaged in decision making and involvement in resilience planning and strategies. Specifically, typologies like Frooman's [61], argue that different relational strategies are called for when the stakeholder is more dependent on the firm, has power over the firm, when there is very little dependence between the focal organization and its stakeholder, and when there is a great deal of interdependence. Knowing the nature of interdependencies enable organizational leaders to make decisions about the types of relationships they enter into, and the amount of time they invest in each relationship. Applying Frooman's arguments to resilience planning, the greater the interdependence between your organization and another organization, the stronger the bond between your organization and that stakeholder. Similarly, Lewis and colleagues [62], pointed to the need to have efficient communication relative to the need to have buy-in from stakeholders in assessing the degree to which to engage them in decision making. These issues for resilience planning are salient because stakeholders are a vital resource for producing and reproducing resilience as the tasks, environment, and overall nature of the disruption changes. Returning to the "S" for stakeholders in the FLOWS approach, then, a resilience officer also needs to consider:

- The degree of interdependency between your organization and its various stakeholders.

- The need for efficiencies versus stakeholder buy in when engaged in resilience planning and disaster preparedness activities.

\section{CONCLUSION}

Organizations develop rules, policies, and standard operating procedures as a way to create predictable environments, consistency in their treatment of people, tasks, and problems, and develop efficiencies to maximize productivity, outputs, and balanced budgets. It makes sense, then, that as natural and manmade disasters become more commonplace, disrupting organizations and communities alike, resilience offices, managers, and task forces are challenged to plan for and manage resilience. The FLOWS approach attempts to unpack five key aspects of the organizational communication part of planning for officers to keep in mind: They should understand the Formality of bureaucratic and network structures their organizations are shaped by, recognize Liaisons who can translate across parts of the system, identify the Overall structure and the Weak ties that carry information around and through the system, and understand their Stakeholders, themselves, for engaging their participation when interdependencies and communication efficiencies call for it. Understanding interorganizational networks is one way resilience officers can anticipate the ways in in which social networks can be leveraged in anticipation of, during, and after extreme events.

\section{REFERENCES}

[1] Aldrich, H., Resource dependence and interorganizational relations. Administration \& Society, 7(4), pp. 419-454, 1976.

[2] Burns, T. \& Stalker, G.M., The Management of Innovation, London: Tavistock, 1961.

[3] Monge, P.R. \& Eisenberg, E.M., Emergent communication networks. Handbook of organizational communication: An interdisciplinary perspective, eds F.M. Jablin, L.L. 
Putnam, K.H. Roberts \& L. W. Porter, Newbury Park, Sage Publications: California, pp. 304-342,1987.

[4] Granovetter, M.S., Economic action and social Structure: The problem of embeddedness. American Journal of Sociology, 91(3), pp. 481-510, 1985.

[5] Isett, K.R. \& Provan, K.G., The evolution of dyadic interorganizational relationships in a network of publicly funded nonprofit agencies. Journal of Public Administration Research and Theory, 15(1), pp. 149-165, 2005.

[6] Provan, K.G. \& Milward, H.B., A preliminary theory of network effectiveness: A comparative study of four community health systems. Administration Science Quarterly, 40(1), pp. 1-33, 1995.

[7] Weick, K.E., The collapse of sensemaking in organizations: The Mann Gulch disaster. Administration Science Quarterly, 38(4), pp. 628-652, 1993.

[8] Weick, K.E. \& Sutcliffe, K.M., Managing the Unexpected: Assuring High Performance in an Age of Complexity. Jossey-Bass: San Francisco, 2001.

[9] Weber, M.S. \& Monge, P.R., Industries in turmoil: Driving transformation during periods of disruption. Communication Research, 44(2), pp. 147-176, 2014.

[10] Eisenberg, E.M. et al., Communication linkages in interorganizational systems. Progress in communication sciences, 6, eds B. Dervin \& M. Voight, Ablex: Norwood, New Jersey, pp. 210-266, 1985.

[11] Doerfel, M.L. Lai, C.H. \& Chewning, L.V., The evolutionary role of interorganizational communication: Modeling social capital in disaster contexts. Human Communication Research, 36(2), pp. 125-162, 2010.

[12] Flanagin, A.J., Monge, P.R. \& Fulk, J., The value of formative investment in organizational federations. Human Communication Research, 27(1), pp. 69-93, 2001.

[13] Taylor, M. \& Doerfel, M.L., Building inter organizational relationships that build nations. Human Communication Research, 29(2), pp. 153-181, 2003.

[14] Weber, M., The Theory of Economic and Social Organization. Free Press: New York, 1964.

[15] Morand, D.A., The role of behavioral formality and informality in the enactment of bureaucratic versus organic organizations. Academy of Management, 20(4), pp. 831$872,1995$.

[16] Aakhus, M. \& Jackson, S., Technology, interaction, and design. Handbook of Language and Social Interaction, eds K. Fitch \& R. Sanders, Lawrence Erlbaum: New Jersey, pp. 411-436, 2005.

[17] Aakhus, M., Communication as design. Communication Monographs ,74(1), pp. 112 117, 2007.

[18] Craig, R.T., Pragmatism in the field of communication theory. Communication. Theory, 9(2), pp. 119-161, 2007.

[19] Jackson, S. \& Aakhus, M., Becoming more reflective about the role of design in communication. Journal of Applied Communication Research, 42(2), 2014.

[20] Albrecht, T.L. \& Ropp, V.A., Communicating about innovation in networks of three U.S. organizations. Journal of Communication, 34(3), pp. 78-91, 1984.

[21] Stevenson, W.B. \& Gilly, M.C., Information processing and problem solving: The migration of problems through formal positions and networks of ties. Academy of Management, 34(4), pp. 918-928, 1991.

[22] Stephens, K.J., Fulk, J. \& Monge, P.R., Constrained choices in alliance formations: Cupids and organizational marriages. Human Relations, 62(4), pp. 501-536, 2009.

[23] Benson, J.K., The interorganizational network as a political economy. Administration Science Quarterly, 20(2), pp. 229-249, 1975. 
[24] Hannan, M.T. \& Freeman, J., The population ecology of organizations. American Journal of Sociology, 82(5), pp. 929-964, 1977.

[25] Hannan, M.T. \& Freeman, J., The ecology of organizational mortality:American labor unions. American Journal of Sociology., 94(1), pp. 25-52, 1988.

[26] Hawley, A.H., Human Ecology. Ronald Press: New York, 1950.

[27] Hawley, A.H., Human ecology: A theoretical essay. University of Chicago Press: Chicago, 1986.

[28] Monge, P.R., Heiss, B.M. \& Margolin, D.B., Communication Network Evolution in Organizational Communities. Communication Theory, 18(4), pp. 449-477, 2008.

[29] Pfeffer, J. \& Salancik, G.R., The External Control of Organizations. Harper \& Row: New York, 1978.

[30] Liebeskind, J.P. \& Oliver, A.L., From handshake to contract: Trust, intellectual property, and the social structure of academic research. Trust within and between organizations, ed. C. Lane \& R. Bachmann, Oxford University Press: Oxford, pp. 118145, 1998.

[31] Oliver, A.L. \& Liebeskind, J.P., Three levels of networking for sourcing intellectual capital in biotechnology. International Studies Management and Organization, 27(4), pp. 76-103, 1998.

[32] Oliver, A.L., The Nexus of organizations and professions: Networking through trusts. Sociological. Inquiry, 67(2), pp. 227-245, 1997.

[33] Diani, M., The Cement of Civil Society. Cambridge University Press: New York, 2015.

[34] Barley, S.R., Freeman, J. \& Hybels, R.C., Strategic alliances in commercial biotechnology. Networks and organizations: Structure, form, and action, ed. N. Nohria \& R.G. Eccles, Harvard Business School Press: Boston, MA, pp. 311-347, 1992.

[35] Cook, K.S., Exchange and power in networks of interorganizational relations. Sociology Quarterly, 18(1), pp. 62-82, 1977.

[36] Emerson, R.M., Power-dependence relations. American Sociological Review, 27(1), pp. 31-41, 1962.

[37] Boje, D.M. \& Whetten, D.A., Effects of organizational strategies and contextual constraints on centrality and attributions of influence in interorganizational networks. Administrative Science Quarterly, 26(3), pp. 378-395, 1981.

[38] Contractor, N.S. \& Monge, P.R., Managing knowledge networks. Management Communication Quarterly, 16(2), pp. 249-258, 2002.

[39] Monge, P.R. \& Contractor, N.S., Theories of Communication Networks. Oxford University Press: New York, 2003.

[40] Kendra, J. \& Wachtendorf, T., American Dunkirk: The Waterborne Evacuation of Manhattan on 9/11. Temple University Press: Philadelphia, 2016.

[41] Burt, R.S., Structural Holes: The Social Structure of Competition .Harvard University Press: Cambridge, MA, 1992.

[42] Coleman, J.S., Social capital in the creation of human capital. American Journal of Sociology, 94 Supplement, pp. s95-s120, 1988.

[43] Lin, N., Building a network theory of social capital. Connections , 22(1), pp. 28-51, 1999.

[44] Podolny, J.M. \& Baron, J.N., Resources and relationships: Social networks and mobility in the workplace. American Sociological Review, 62(5), pp. 673-693, 1997.

[45] Janis, I., Victims of Groupthing. Houghton Mifflin: Boston, MA, 1972.

[46] Soda, G., Usai, A. \& Zaheer, A.,Network memory: The influence of past and current networks on performance. Academy of Management Journal, 47(6), pp. 893-906, 2004. 
[47] The Economic Impact of Civil Aviation on the U.S. Economy. U.S. Department of Transportation Federal Aviation Administration, 2015.

[48] Uzzi, B., Social structure and competition in interfirm networks: The paradox of embeddedness. Administrative Science Quarterly, 42(1), pp. 35-67, 1997.

[49] Bennett, W.L. \& Segerberg, A.,The Logic of Connective Action: Digital Media and the Personalization of Contentious Politics. Cambridge University Press: New York, 2013.

[50] Granovetter, M.S., The strength of weak ties.American Journal of Sociology, 78(6), pp. 1360-1380, 1973.

[51] Granovetter, M.S., The strength of weak ties: A network theory revisited.Sociological Theory, 1, pp. 201-233, 1983.

[52] Marsden, P.V. \& Campbell, K.E., Measuring tie strength. Social Forces, 63(2), pp. 482-501, 1984.

[53] Perry-Smith, J.E. \& Shalley, C.E., The social side of creativity: A static and dynamic social network perspective. Academy of Management Review, 28(1), pp. 89-106, 2003.

[54] Doerfel, M.L. \& Haseki, M., Networks, disrupted: Media use as an organizing mechanism for rebuilding. New Media and Society, 17(3), 2013.

[55] Yuan, Y.C., Fulk, J., Monge, P.R. \& Contractor, N.S.,Expertise directory development, shared task interdependence, and strength of communication network ties as multilevel predictors of expertise exchange in transactive memory workgroups. Communication Research, 37(1), pp. 20-47, 2010.

[56] Gibbons, D.E., Interorganizational network structures and diffusion of information through a health system. American Journal of Public Health, 97(9), pp. 1684-1692, 2007.

[57] Michelfelder, I. \& Kratzer, J., Why and how combining strong and weak ties within a single interorganizational R\&D collaboration outperforms other collaboration structures. Journal of Product Innovation Management, 30(6), pp. 1159-1177, 2013.

[58] Doerfel, M.L. \& Taylor, M., Network dynamics of inter organizational cooperation: The Croatian civil society movement. Communication Monographs., 71(4), pp. 373394, 2004.

[59] Freeman, R.E., Strategic Management: A Stakeholder Approach. Pitman: Boston, MA.

[60] Doerfel, M.L., Chewning, L.V. \& Lai, C.H., The evolution of networks and the resilience of interorganizational relationships after disaster. Communication. Monographs, 80(4), pp. 533-559, 2013.

[61] Frooman, J., Stakeholder influence strategies. Academy of Management Review ,24(2), pp. 191-205, 1999.

[62] Lewis, L.K., Hamel, S.A. \& Richardson, B.K., Communicating change to nonprofit stakeholders: Models and predictors of implementers' approaches. Management Communication Quarterly, 15(5), pp. 5-41, 2001. 